\title{
The Electrochemical Behavior and Heat Removal Study during the Solidification Process of an Al-base Alloy
}

\author{
O.R. Pérez ${ }^{1,2}$, O. Sotelo ${ }^{l}$, M. Vázquez ${ }^{1,2}$, S. Valdez $z^{1, *}$ \\ ${ }^{1}$ Instituto de Ciencias Físicas-UNAM, Av. Universidad 1001, Col. Chamilpa, 062210, Cuernavaca, \\ Morelos, México. \\ ${ }^{2}$ Universidad Autónoma del Estado de Morelos-Research center in engineering and applied sciences, \\ Av. Universidad 1001, Col. Chamilpa, 62210, Cuernavaca, Morelos, México. \\ *E-mail: svaldez@ fis.unam.mx
}

doi: $10.20964 / 2017.01 .55$

Received: 25 October 2016 / Accepted: 19 November 2016 / Published: 12 December 2016

\begin{abstract}
We study the effect that physicochemical phenomena attack the electrochemical degradation of ternary aluminum alloy. The chemical reaction on corrosion behavior has been correlated with extraction of heat during the solidification process. The scope of the present work is the analysis of the evolution of chemical degradation into aluminum alloys by the influence of the imposing high cooling rate during liquid to solid formation. Within the framework of a thermodynamic phenomenon, the cooling rate has been estimated as the single most important influence on the microstructural behavior. The first approach involves the effects of dendrite arm size and the solute distribution for the ternary aluminum alloy. In fact, the extreme rates of heat removal have been correlated with a good corrosion resistance for the aluminum alloy, which has been linked with the appropriate composition and refined microstructural features. Moreover, the evolution of the growth rate of the solid, which occurs during the casting, might lead both to their mechanical properties, and chemical degradation. Several metallic systems have been considered for use as approach to explain of such chemical mechanism to corrosion degradation. The effect of electrochemical parameters such as $\mathrm{E}_{\text {corr }}$ and $\mathrm{I}_{\text {corr }}$ values has been deduced, and will also be discussed the initial corrosion kinetics and the corrosion resistance behavior.
\end{abstract}

Keywords: Electrochemical degradation, Electrochemical Impedance Spectroscopy, Bode phase diagram, aluminum base alloys, cooling rate, solidification process.

\section{FULL TEXT}

(C) 2017 The Authors. Published by ESG (www.electrochemsci.org). This article is an open access article distributed under the terms and conditions of the Creative Commons Attribution license (http://creativecommons.org/licenses/by/4.0/). 